\title{
Effects of Otago exercise combined with action observation training on balance and gait in the old people
}

\author{
Soo-Hyun Leem ${ }^{1}$, Jung-Hee Kim² ${ }^{2}$ Byoung-Hee Lee ${ }^{3, *}$ \\ ${ }^{1}$ Graduate School of Physical Therapy, Sahmyook University, Seoul, Korea \\ 2Department of Physical Therapy, Andong Science College, Andong, Korea \\ ${ }^{3}$ Department of Physical Therapy, Sahmyook University, Seoul, Korea
}

This study aimed to investigate the effects of Otago exercise combined with action observation ( $\mathrm{AO}$ ) training on the balance, and gait in the old people to prevent falls in the community. A total of 30 old women participated and randomly assigned into three groups: $A 0$ plus Otago $(n=10)$, Otago $(n=10)$, or control $(n=10)$. The AO plus Otago and Otago groups performed 50 min of strength training and balance exercises from the Otago Exercise Program 3 times a week for 12 weeks. The AO plus Otago group received an additional 20 min of training 3 times a week. We used the electronic muscle dynamometer to changes in strength, Timed Up and Go (TUG) test to evaluate dynamic balance, and the short version of the Falls Efficacy Scale-International was used to evaluate the fear of falls, and GAITRite was used to evaluate changes in the spatiotemporal parameters of walking. The muscle strength significantly in- creased in the $\mathrm{AO}$ plus Otago and Otago groups compared to the strength before training. The TUG test showed a significant improvement in the dynamic balance in both intervention groups. A significant increase was observed in the walking speed, cadence, step length, and stride length in both intervention groups. We also noted a significant change in the efficacy measures for falls. It is expected that Otago exercise combined with $\mathrm{AO}$ training will be used as an intervention method in hospital treatment programs and the old people facilities for preventing falls in the old people.

Keywords: Action observation, Otago exercise, Old people, Gait, balance, Prevent falls

\section{INTRODUCTION}

Fall-related factors in older people include reduced self-efficacy, increased fear of falls, reduced mobility, and poor balance (Guccione et al., 1994; Hosseini et al., 2018). Intervention methods to prevent falls in the old people include balance and posture control (Borel L and Alescio-Lautier, 2014) through tai chi exercise programs (Son et al., 2016), gait training (Lelard et al., 2010), posture control and mobility training through yoga programs (Clark and Kraemer, 2009), strength training using the resistance of elastic bands (Kamide et al., 2009), and balance exercises on smooth ground (Bishop et al., 2007).

The Otago Exercise Program, which consists of muscle strength exercises, balance training, and walking, was invented and widely applied at Otago University in New Zealand. In a previous study of the Otago Exercise Program, men and women over 70 years old were randomly divided into experimental and control groups, and Otago exercise was shown to improve balance ability, increase muscle strength, and reduce fall risk (Liu-Ambrose et al., 2008). A meta-analysis of 1,503 people using the Otago Exercise Program reported a reduction in the mortality rate and fall risk of the old people in the community (Thomas et al., 2010). Action observation is a cognitive intervention training method that induces motor learning through observation of other people's performance (De Vries and Mulder, 2007). The excitability of the primary motor cortex is increased during action observation training (Iacoboni, 2005), and the combination of action observation and physical training strongly promotes the development of motor memory (Gangitano et al., 2001). Action observation has been shown to have a positive effect on recovery from motor damage in patients
${ }^{*}$ Corresponding author: Byoung-Hee Lee (iD https://orcid.org/0000-0001-9766-6068 Department of Physical Therapy, Sahmyook University, 815 Hwarang-ro,

Nowon-gu, Seoul 01795, Korea

E-mail:3679@syu.ac.kr

Received: November 15, 2019 / Accepted: December 14, 2019
This is an Open Access article distributed under the terms of the Creative Commons Attribution Non-Commercial License (http://creativecommons.org/licenses/by-nc/4.0/) which permits unrestricted non-commercial use, distribution, and reproduction in any medium, provided the original work is properly cited. 
with stroke and Parkinson (Buccino et al., 2006; Pelosin et al., 2018). When action observation training, including standing, sitting, and walking training, was performed on the old people, its benefits on walking speed, increasing the number of strides, and shortening of sitting time in the standing position were confirmed (Tia et al., 2010). Action observation training has been shown to be effective at improving motor performance in the old people (Bellelli et al., 2010; Kawasaki et al., 2018). This study aimed to investigate the effects of Otago exercise combined with action observation training on the old people's muscle strength, balance, fall efficacy, and walking ability.

\section{MATERIALS AND METHODS}

This study was conducted with 30 old women subjects recruited from Seoul who understood the research and were willing to participate. Inclusion criteria for the study were: female, over 70 years old, and with a minimum Mini-Mental State Examination-Korea score of 24. The exclusion criteria were as follows: cardiovascular or cerebrovascular disease, traumatic brain injury, epilepsy, abnormalities in visual, auditory, or vestibular organs, limb defects, and fractures within the previous year. This study was approved by the Ethics Committee (Sahmyook University Institutional Review Board, SYUIRB2014-068), and the objective of the study and its requirements were explained to all participants before conduct of the experiment, and all participants signed a written informed consent form; thus, the rights of human subjects were protected. The 30 subjects were randomly divided into the following three groups: AO plus Otago group $(\mathrm{n}=10)$, Otago group $(\mathrm{n}=10)$, and control group $(n=10)$ (Table 1). Action observation training was conducted 3 times a week for 20 min per session, and Otago exercise training was conducted 3 times a week for a total of $50 \mathrm{~min}$ per session, including $5 \mathrm{~min}$ of warm-up and $5 \mathrm{~min}$ of cool-down and relaxation exercises to finish. To minimize confounding variables, during the 12-week experimental period the control group

Table 1. General characteristics of subject

\begin{tabular}{lrrrr}
\hline Characteristic & \multicolumn{1}{c}{$\begin{array}{c}\text { A0+0tago } \\
(\mathrm{n}=10)\end{array}$} & \multicolumn{1}{c}{$\begin{array}{c}\text { Otago } \\
(\mathrm{n}=10)\end{array}$} & \multicolumn{1}{c}{$\begin{array}{c}\text { Control } \\
(\mathrm{n}=10)\end{array}$} & $F(P$-value $)$ \\
\hline Ages $(\mathrm{yr})$ & $79.50 \pm 4.55$ & $76.30 \pm 5.16$ & $81.10 \pm 3.07$ & $3.153(0.059)$ \\
Height $(\mathrm{cm})$ & $148.20 \pm 8.28$ & $152.00 \pm 4.71$ & $147.70 \pm 3.83$ & $1.572(0.226)$ \\
Weight $(\mathrm{kg})$ & $57.10 \pm 4.33$ & $58.20 \pm 5.53$ & $55.30 \pm 3.68$ & $1.021(0.374)$ \\
MMSE-K (score) & $29.50 \pm 0.71$ & $29.40 \pm 0.84$ & $29.70 \pm 0.67$ & $0.420(0.661)$ \\
\hline
\end{tabular}

Values are expressed as mean \pm standard deviation.

AO, action observation; MMSE-K, Korean version of Mini-Mental State Examination. avoided exercise related to strength, balance, and participated in the same social activities as the experimental group, except for the exercise training.

\section{Otago Exercise Program}

The Otago Exercise Program is designed to prevent falls and is composed of strength training and balance training for the old people. Strength training consisted of flexion and extension exercises of the knee, ankle, and toe joints, as well as hip opening exercises to strengthen the sides of the pelvis. Balance training consisted of walking backwards, walking in a figure of eight, heel-toe walking, standing on one leg, walking on the heels, walking on the toes, heel-toe walking backwards, standing up from a sitting position, and walking up stairs. Strength training and balance training were conducted 3 times a week under the supervision of a therapist. Training lasted for 40 min followed by 5 min of warm-up and 5 min of cool-down, relaxation exercises to finish.

\section{Otago Exercise Program combined with action observation training}

Action observation training was conducted based on the Otago Exercise Program. Participants were asked to watch a video on a 45 -inch screen placed $2 \mathrm{~m}$ away from them while sitting comfortably in a chair with armrests. While watching the video, participants were not allowed to follow along or move around. The model in the video was 70 years old or older like the participants. The viewing time of the video was $20 \mathrm{~min}$ and, after watching, $50 \mathrm{~min}$ of physical training was conducted with the therapist based on the content of the video. In order to enhance the effectiveness of action observation training, video viewing was conducted at a designated time in a quiet place without noise and was overseen by the same investigator from the beginning to the end of the study. The content of the video watched during the action observation training sessions consisted of the same exercises that were performed during the physical training sessions.

\section{Outcome measures}

An electronic muscle dynamometer (Model 01163, Lafayette Instrument Co., Lafayette, IN, USA) was used to measure the muscle strength of hip flexion, ankle dorsiflexion, and plantar flexion. Hip flexion muscle strength was measured while subjects flexed the hip and knee joints $90^{\circ}$ in the side-lying position. The dynamometer was placed on the distal front of the thigh and the subject was asked to hold the limb in position. The examiner applied a force to the thigh in the direction of extension for $5 \mathrm{sec}$ and the 
dynamometer measured the subject's resistance to this force.

Ankle dorsiflexion muscle strength was measured with the dynamometer positioned at the dorsal surface of the metatarsal bones with the subject in the side-lying position. Plantar flexion muscle strength was measured with the dynamometer positioned on the plantar side of the metatarsal bones. In both cases, the subject attempted to hold their foot in position while the examiner applied a force to the metatarsal bones for $5 \mathrm{sec}$. Measurements were repeated 3 times and the mean values were used.

The Timed Up and Go (TUG) test was conducted to evaluate changes in dynamic balance following the intervention. The subject began in a seated position. At a start signal, they stood up, walked $3 \mathrm{~m}$ away, turned around, walked back, and returned to a seated position. The time was measured from the start signal to when the subject was seated in the chair again (Chan et al., 2017).

The GAITRite walkway system (GAITRite, CIR Systems Inc., Franklin, NJ, USA) was used to measure temporal and spatial gait parameters (Rehman et al., 2019). The device consisted of an electronic walkway $5 \mathrm{~m}$ long and $61 \mathrm{~cm}$ wide, with 16,128 sensors arranged to collect information about temporal and spatial variables. Subjects started at the front of the walkway and, at the examiner's verbal signal, walked along the walkway at their most comfortable walking speed. Spatiotemporal gait parameters such as velocity, cadence, step length, and stride length were measured. The intraclass reliability of this test has been reported as 0.90 and the interclass reliability as 0.96 (Van Uden and Besser, 2004). Measurements were repeated 3 times and the mean values were used.

Fear of falling was assessed using the short version of the Falls

Table 2. Difference on muscle strength

\begin{tabular}{|c|c|c|c|c|c|}
\hline Variable & $A 0+0 \operatorname{tago}(n=10)(A)$ & Otago $(n=10)(B)$ & Control $(n=10)(C)$ & $F(P$-value $)$ & Posthoc \\
\hline \multicolumn{6}{|c|}{ Right hip flexion (kg) } \\
\hline Pretest & $8.08 \pm 1.31$ & $7.80 \pm 0.86$ & $8.13 \pm 0.64$ & & \\
\hline Posttest & $15.16 \pm 1.13$ & $13.10 \pm 0.89$ & $8.23 \pm 0.60$ & & \\
\hline Prepost & $-7.08 \pm 1.65$ & $-5.48 \pm 0.79$ & $-0.10 \pm 0.28$ & $116.180(0.000)$ & $\mathrm{A}|\mathrm{B}| \mathrm{C}$ \\
\hline$t(P$-value $)$ & $-13.542(0.000)$ & $-21.699(0.000)$ & $-1.108(0.297)$ & & \\
\hline \multicolumn{6}{|c|}{ Left hip flexion (kg) } \\
\hline Pretest & $8.06 \pm 1.33$ & $7.83 \pm 0.74$ & $8.18 \pm 0.72$ & & \\
\hline Posttest & $15.20 \pm 0.74$ & $13.31 \pm 1.02$ & $8.21 \pm 0.61$ & & \\
\hline Prepost & $-7.14 \pm 1.64$ & $-5.48 \pm 0.55$ & $-0.33 \pm 0.46$ & $128.320(0.000)$ & $A|B| C$ \\
\hline$t(P$-value $)$ & $-13.710(0.000)$ & $-31.385(0.000)$ & $-0.227(0.825)$ & & \\
\hline \multicolumn{6}{|c|}{ Right dorsiflexion (kg) } \\
\hline Pretest & $7.36 \pm 1.04$ & $7.23 \pm 0.52$ & $7.46 \pm 0.55$ & & \\
\hline Posttest & $11.21 \pm 0.70$ & $9.48 \pm 0.72$ & $7.58 \pm 0.46$ & & \\
\hline Prepost & $-3.85 \pm 0.54$ & $-2.25 \pm 0.95$ & $-0.11 \pm 0.30$ & $80.900(0.000)$ & $A|B| C$ \\
\hline$t(P$-value $)$ & $-22.469(0.000)$ & $-7.438(0.000)$ & $-1.210(0.257)$ & & \\
\hline \multicolumn{6}{|c|}{ Left dorsiflexion (kg) } \\
\hline Pretest & $7.38 \pm 1.02$ & $7.16 \pm 0.57$ & $7.61 \pm 0.53$ & & \\
\hline Posttest & $10.96 \pm 0.74$ & $9.57 \pm 0.78$ & $7.61 \pm 0.49$ & & \\
\hline Prepost & $-3.58 \pm 0.54$ & $-2.40 \pm 0.93$ & $0.00 \pm 0.30$ & $78.909(0.000)$ & $\mathrm{A}|\mathrm{B}| \mathrm{C}$ \\
\hline$t(P$-value $)$ & $-20.982(0.000)$ & $-8.085(0.000)$ & $0.000(0.100)$ & & \\
\hline \multicolumn{6}{|c|}{ Right plantar flexion (kg) } \\
\hline Pretest & $7.41 \pm 0.88$ & $7.48 \pm 0.55$ & $7.51 \pm 0.56$ & & \\
\hline Posttest & $13.36 \pm 0.53$ & $11.73 \pm 1.33$ & $7.40 \pm 0.63$ & & \\
\hline Prepost & $-5.95 \pm 0.67$ & $-4.24 \pm 1.43$ & $0.11 \pm 0.32$ & $112.631(0.000)$ & $A|B| C$ \\
\hline$t(P$-value $)$ & $-28.020(0.000)$ & $-9.376(0.000)$ & $1.137(0.285)$ & & \\
\hline \multicolumn{6}{|c|}{ Left plantar flexion $(\mathrm{kg})$} \\
\hline Pretest & $7.36 \pm 0.93$ & $7.18 \pm 0.58$ & $7.60 \pm 0.53$ & & \\
\hline Posttest & $13.71 \pm 0.64$ & $11.76 \pm 1.15$ & $7.48 \pm 0.63$ & & \\
\hline Prepost & $-6.36 \pm 0.88$ & $-4.53 \pm 1.28$ & $0.11 \pm 0.43$ & $127.409(0.000)$ & $A|B| C$ \\
\hline$t(P$-value $)$ & $-22.729(0.000)$ & $-9.376(0.000)$ & $0.857(0.414)$ & & \\
\hline
\end{tabular}

Values are expressed as mean \pm standard deviation.

$A 0$, action observation. 
Efficacy Scale-International (Short FES-I). In this questionnaire, there were seven questions and for each question the lowest possible score was one and the highest possible score was four. Lower scores indicated that the subject had more confidence that they would not fall (Kempen et al., 2008). A total score of 7-8 was classified as little or no fear of falling, 9-13 as moderate fear of falling, and 14 or more as severe fear of falling (Delbaere et al., 2010). The Cronbach alpha coefficient of test-retest reliability for the Short FES-I has been reported as 0.93 (Kovács et al., 2018). Preintervention and postintervention evaluations were performed by the same investigator and were conducted through one-on-one interviews with the subjects.

\section{Data analysis}

All statistical analyses in this study were conducted using IBM SPSS Statistics ver. 20.0 (IBM Co., Armonk, NY, USA). The Shapiro-Wilk test was used to assess the normality of the distribution of the data. The general characteristics of the subjects were expressed using descriptive statistics. Paired $t$-tests were performed to compare outcome measures before and after the intervention in each group. One-way analysis of variance was performed to compare differences in outcomes according to the different interven- tions that each group received. post hoc analysis was performed using Tukey Honestly Significant Difference test. $P<0.05$ was considered statistically significant.

\section{RESULTS}

There were statistically significant differences between the preintervention and postintervention measurements in both the $\mathrm{AO}$ plus Otago and the Otago groups $(P<0.05)$.

Both the AO plus Otago and the Otago groups showed significant increases in right-side plantar flexion muscle strength after training $(P<0.05)$ (Table 2$)$. In the TUG test, both intervention groups also showed the following significant improvements: the AO plus Otago group decreased the time by $4.08 \mathrm{sec}(16.17 \mathrm{sec}$ to $12.08 \mathrm{sec}, P<0.05)$, and the Otago group decreased the time by $3.76 \mathrm{sec}(16.56 \mathrm{sec}$ to $12.79 \mathrm{sec}, P<0.05)$ (Table 3 ).

Both intervention groups also showed significant improvements in their temporal gait parameters. The AO plus Otago group increased the walking speed by $20.30 \mathrm{~cm} / \mathrm{sec}(79.64 \mathrm{~cm} / \mathrm{sec}$ to 99.94 $\mathrm{cm} / \mathrm{sec}, P<0.05)$, and the Otago group increased their speed by $16.90 \mathrm{~cm} / \mathrm{sec}(78.52 \mathrm{~cm} / \mathrm{sec}$ to $95.42 \mathrm{~cm} / \mathrm{sec}, P<0.05)$. The AO plus Otago group increased their cadence by 17.35 steps $/ \mathrm{min}$ ( 99.80

Table 3. Difference on dynamic balance

\begin{tabular}{|c|c|c|c|c|c|}
\hline TUG test & $A 0+0 \operatorname{tago}(n=10)(A)$ & Otago $(n=10)(B)$ & Control $(n=10)(C)$ & $F(P$-value $)$ & Posthoc \\
\hline Pretest & $16.17 \pm 1.99$ & $16.56 \pm 1.67$ & $14.96 \pm 2.98$ & & \\
\hline Posttest & $12.08 \pm 3.92$ & $12.79 \pm 1.80$ & $15.04 \pm 3.34$ & & \\
\hline Prepost & $4.08 \pm 2.19$ & $3.76 \pm 1.22$ & $-0.08 \pm 0.37$ & $24.954(0.000)$ & $\mathrm{A}, \mathrm{B} \mid \mathrm{C}$ \\
\hline$t(P$-value $)$ & $5.882(0.000)$ & $9.738(0.000)$ & $-0.679(0.514)$ & & \\
\hline
\end{tabular}

Values are expressed as mean \pm standard deviation.

TUG test, Timed Up and Go test; AO, action observation.

Table 4. Difference on temporal gait parameter

\begin{tabular}{|c|c|c|c|c|c|}
\hline Variable & $A 0+0 \operatorname{tago}(n=10)(A)$ & Otago $(n=10)(B)$ & Control $(n=10)(C)$ & $F(P$-value $)$ & Posthoc \\
\hline \multicolumn{6}{|c|}{ Gait speed (cm/sec) } \\
\hline Pretest & $79.64 \pm 7.75$ & $78.52 \pm 4.51$ & $81.31 \pm 11.10$ & & \\
\hline Posttest & $99.94 \pm 7.13$ & $95.42 \pm 19.38$ & $81.26 \pm 15.96$ & & \\
\hline Prepost & $-20.30 \pm 11.00$ & $-16.90 \pm 19.87$ & $0.05 \pm 21.14$ & $3.770(0.036)$ & $\mathrm{A}, \mathrm{B} \mid \mathrm{C}$ \\
\hline$t(P$-value $)$ & $-5.835(0.000)$ & $-2.690(0.025)$ & $0.007(0.994)$ & & \\
\hline \multicolumn{6}{|c|}{ Cadence (step/min) } \\
\hline Pretest & $99.80 \pm 21.55$ & $105.01 \pm 3.50$ & $108.62 \pm 8.75$ & & \\
\hline Posttest & $117.16 \pm 7.31$ & $115.92 \pm 13.15$ & $108.31 \pm 8.30$ & & \\
\hline Prepost & $-17.35 \pm 23.65$ & $-10.91 \pm 13.22$ & $0.31 \pm 1.83$ & $6.797(0.004)$ & $\mathrm{A}, \mathrm{B} \mid \mathrm{C}$ \\
\hline$t(P$-value $)$ & $-2.321(0.045)$ & $-2.610(0.028)$ & $0.530(0.609)$ & & \\
\hline
\end{tabular}

Values are expressed as mean \pm standard deviation.

$A 0$, action observation. 
Table 5. Difference spatial gait parameter

\begin{tabular}{|c|c|c|c|c|c|}
\hline Variable & $A 0+0 \operatorname{tago}(n=10)(A)$ & Otago $(n=10)(B)$ & Control $(n=10)(C)$ & $F(P$-value $)$ & Posthoc \\
\hline \multicolumn{6}{|c|}{ Right step length (cm) } \\
\hline Pretest & $41.72 \pm 6.14$ & $38.97 \pm 7.88$ & $42.14 \pm 6.12$ & & \\
\hline Posttest & $51.32 \pm 3.49$ & $47.15 \pm 7.59$ & $44.06 \pm 6.44$ & & \\
\hline Prepost & $-9.59 \pm 5.53$ & $-8.18 \pm 3.39$ & $-1.91 \pm 8.98$ & $4.141(0.027)$ & $\mathrm{A}|\mathrm{B}| \mathrm{C}$ \\
\hline$t(P$-value $)$ & $-5.668(0.000)$ & $-7.613(0.000)$ & $-0.676(0.516)$ & & \\
\hline \multicolumn{6}{|c|}{ Left step length (cm) } \\
\hline Pretest & $43.30 \pm 6.91$ & $39.47 \pm 6.14$ & $41.29 \pm 6.12$ & & \\
\hline Posttest & $51.82 \pm 3.17$ & $47.87 \pm 5.91$ & $45.21 \pm 7.27$ & & \\
\hline Prepost & $-8.51 \pm 5.54$ & $-8.40 \pm 4.43$ & $-3.91 \pm 9.55$ & $1.460(0.250)$ & $\mathrm{A}|\mathrm{B}| \mathrm{C}$ \\
\hline$t(P$-value $)$ & $-4.852(0.010)$ & $-5.999(0.000)$ & $-1.296(0.227)$ & & \\
\hline \multicolumn{6}{|c|}{ Right stride length (cm) } \\
\hline Pretest & $85.30 \pm 12.87$ & $78.78 \pm 13.65$ & $83.44 \pm 11.78$ & & \\
\hline Posttest & $104.11 \pm 5.49$ & $95.31 \pm 13.01$ & $89.42 \pm 14.06$ & & \\
\hline Prepost & $-18.80 \pm 11.45$ & $-16.52 \pm 8.12$ & $-5.97 \pm 17.45$ & $2.800(0.078)$ & $\mathrm{A}|\mathrm{B}| \mathrm{C}$ \\
\hline$t(P$-value $)$ & $-5.192(0.001)$ & $-6.430(0.000)$ & $-1.083(0.307)$ & & \\
\hline \multicolumn{6}{|c|}{ Left stride length (cm) } \\
\hline Pretest & $85.29 \pm 12.94$ & $78.77 \pm 14.13$ & $83.72 \pm 12.70$ & & \\
\hline Posttest & $103.81 \pm 5.81$ & $95.50 \pm 13.07$ & $89.68 \pm 13.90$ & & \\
\hline Prepost & $-18.52 \pm 10.33$ & $-16.73 \pm 7.59$ & $-5.96 \pm 18.55$ & $2.724(0.084)$ & $\mathrm{A}|\mathrm{B}| \mathrm{C}$ \\
\hline$t(P$-value $)$ & $-5.669(0.000)$ & $-6.973(0.000)$ & $-1.016(0.336)$ & & \\
\hline
\end{tabular}

Values are expressed as mean \pm standard deviation.

$\mathrm{AO}$, action observation.

Table 6. Difference on self-efficacy of fall down

\begin{tabular}{|c|c|c|c|c|c|}
\hline Variable & $A 0+0$ tago $(n=10)(A)$ & Otago $(n=10)(B)$ & Control $(n=10)(C)$ & $F(P$-value $)$ & Posthoc \\
\hline \multicolumn{6}{|c|}{ Short efficacy scale } \\
\hline Pretest & $17.20 \pm 4.15$ & $18.10 \pm 3.57$ & $16.70 \pm 2.98$ & & \\
\hline Posttest & $11.50 \pm 3.92$ & $3.109 \pm 3.28$ & $16.40 \pm 2.24$ & & \\
\hline Prepost & $-5.70 \pm 2.11$ & $-5.00 \pm 1.94$ & $-0.30 \pm 0.82$ & $29.031(0.000)$ & $\mathrm{A}|\mathrm{B}| \mathrm{C}$ \\
\hline$t(P$-value $)$ & $8.539(0.000)$ & $8.135(0.000)$ & $1.152(0.279)$ & & \\
\hline
\end{tabular}

Values are expressed as mean \pm standard deviation.

$A 0$, action observation.

steps/min to 117.16 steps/min, $P<0.05)$ and the Otago group increased theirs by $10.91 \mathrm{steps} / \mathrm{min}$ (105.61 steps/min to 115.92 steps/min, $P<0.05$ ) (Table 4).

Both intervention groups also showed significant improvements in their spatial gait parameters: the AO plus Otago group and the Otago group both showed significant increases in step length $(P<$ $0.05)$ and in right-side stride length after training $(P<0.05)$ ( Table 5).

Both intervention groups also showed the following significant improvement in the fear of falling: the AO plus Otago group decreased their Short FES-I score by 5.7 points (17.2 points to 11.5 points, $P<0.05)$ and the Otago group decreased the score by 5.0 points (18.1 points to 13.1 points, $P<0.05$ ) (Table 6).

\section{DISCUSSION}

Weakness of the hip flexor muscle makes toe clearance during the initial swing phase of walking difficult and can lead to an increased risk of falls. In addition, the strength of the ankle flexors and plantar flexors are closely related to continuous performance of the gait cycle. In a previous study, the experimental group performed 70 min of muscle strength and balance exercise according to the Otago Exercise Program 3 times a week and 30 min of walking exercise twice a month for 6 months. As a result, hip flexion strength increased from $21.7 \mathrm{~kg}$ to $22.0 \mathrm{~kg}$ (Liu-Ambrose et al., 2008).

In this study, hip flexor muscle strength in the $\mathrm{AO}$ plus Otago 
group significantly increased on both the right side $(8.08 \mathrm{~kg}$ to $15.16 \mathrm{~kg}$ ) and the left side (8.06 kg to $15.20 \mathrm{~kg}$ ), consistent with previous studies. There was also a significant increase in muscle strength of the hip flexor muscles on both sides in the Otago group.

In the $\mathrm{AO}$ plus Otago group, the left and right hip flexor strength increased by $7.08 \mathrm{~kg}$ and $7.14 \mathrm{~kg}$, respectively, and in the Otago group, the strength of both sides increased by $5.48 \mathrm{~kg}$. Muscle strength of the hip flexor muscles increased more in the $\mathrm{AO}$ plus Otago group, and there was a significant difference in the post hoc test. These results show the combination of the effects of action observation training, which induces the improvement of exercise performance by providing an accurate understanding of movement, with the effects of muscle strengthening according to the execution of the Otago Exercise Program, which is composed of exercises for the lower limb joints.

In this study, a TUG test was conducted to assess changes in dynamic balance ability. The average time taken for the TUG test by the subjects aged in their $60 \mathrm{~s}$ was $8-13.1 \mathrm{sec}$, and if it took them $14 \mathrm{~s}$ or more, they were at increased risk of falling (Bohannon, 2006). In this study, the $\mathrm{AO}$ plus Otago group showed a significant decrease in time taken to complete the test $(16.17 \mathrm{sec}$ before training to $11.50 \mathrm{sec}$ after training). The Otago group also decreased their time (16.56 sec before training to $12.79 \mathrm{sec}$ after training), which was consistent with previous studies. It is thought that the $\mathrm{AO}$ plus Otago intervention helped the subjects better understand the movements and remember the detailed postures and procedures by repeatedly observing the movements. Participants in the AO plus Otago group watched performances of the Otago Exercise Program for 20 min, such as walking backwards, walking sideways, walking around, standing in line, walking in line, and walking on toes and heels. The action observation helped to improve the understanding of the movements such as the sequence of movements to be performed and the detailed posture, and the audiovisual information presented through the videos may have helped to stimulate the motor cortex. In addition, it is thought that improved balance ability was also induced through the action observation and physical training in the movements requiring high levels of balance such as walking on the heels, walking in a line, walking sideways, etc. during the Otago exercises. A previous study applied augmented-reality-based Otago exercise which included strength and balance training to a 70-year-old woman 3 times a week for 60 min per session, for 3 months, and her walking speed increased from $0.80 \mathrm{~m} / \mathrm{sec}$ before training to $0.97 \mathrm{~m} / \mathrm{sec}$ after training (Yoo et al., 2013). In this study, the AO plus Otago group showed a significant increase from $0.79 \mathrm{~m} / \mathrm{sec}$ before train- ing to $0.99 \mathrm{~m} / \mathrm{sec}$ after training.

The Otago Exercise Program included various forms of walking exercises, such as walking backwards, walking in a figure of eight, walking sideways, walking straight, and walking up the stairs, which consistently induced the activity of flexion muscles of the hip and isotonic flexion of the ankles. This may have contributed to the improvement of muscle strength and coordination. Especially, the combination of action observation and Otago exercise induced an increased understanding of motion and increased excitement of related brain areas such as the motor cortex, and the combination training was shown to improve balance ability and increase walking speed in actual performance.

In the fall efficacy assessment, the $\mathrm{AO}$ plus Otago group showed a significant decrease from 17.2 points before training to 11.5 points after training. In the Otago group, there was also a significant decrease from 18.1 points to 13.1 points, which is consistent with the previous studies.

Efficacy can be improved through the experience of repeating and achieving the desired task. If you are not confident about the execution of an action, the action is difficult to perform smoothly. Stronger self-efficacy means more effort for performance and longer duration for effort. In this study, the $\mathrm{AO}$ plus Otago group received repeated visual feedback on the performance of the Otago exercises and also repeatedly performed the Otago exercise step by step. For this reason, the participants in the AO plus Otago group are thought to have benefited from a greater effect of the staged achievement of task performance than the other groups. Experience of achievement reduced the fear of falls and may have influenced the improvement of fall efficacy. The results of this study showed that Otago exercise combined with action observation training had positive effects on muscle strength, dynamic balance, fall efficacy, and walking ability of the old people. It is hoped that Otago exercise combined with action observation training will be used to prevent falls in clinical and the old people facilities.

\section{CONFLICT OF INTEREST}

No potential conflict of interest relevant to this article was reported.

\section{ACKNOWLEDGMENTS}

This study was supported by a grant from the NRF (NRF2018R1D1A1B07045746), which is funded by the Korean government. 


\section{REFERENCES}

Bellelli G, Buccino G, Bernardini B, Padovani A, Trabucchi M. Action observation treatment improves recovery of postsurgical orthopedic patients: evidence for a top-down effect? Arch Phys Med Rehabil 2010; 91:1489-1494.

Bishop MD, Meuleman J, Robinson M, Light KE. Influence of pain and depression on fear of falling, mobility, and balance in older male veterans. J Rehabil Res Dev 2007;44:675-683.

Bohannon RW. Reference values for the timed up and go test: a descriptive meta-analysis. J Geriatr Phys Ther 2006;29:64-68.

Borel L, Alescio-Lautier B. Posture and cognition in the elderly: interaction and contribution to the rehabilitation strategies. Neurophysiol Clin 2014;44:95-107.

Buccino G, Solodkin A, Small SL. Functions of the mirror neuron system: implications for neurorehabilitation. Cogn Behav Neurol 2006;19:55-63.

Chan PP, Si Tou JI, Tse MM, Ng SS. Reliability and validity of the Timed Up and Go test with a motor task in people with chronic stroke. Arch Phys Med Rehabil 2017;98:2213-2220.

Clark R, Kraemer T. Clinical use of Nintendo Wii bowling simulation to decrease fall risk in an elderly resident of a nursing home: a case report. J Geriatr Phys Ther 2009;32:174-180.

de Vries S, Mulder T. Motor imagery and stroke rehabilitation: a critical discussion. J Rehabil Med 2007;39:5-13.

Delbaere K, Close JC, Mikolaizak AS, Sachdev PS, Brodaty H, Lord SR. The Falls Efficacy Scale International (FES-I). A comprehensive longitudinal validation study. Age Ageing 2010;39:210-216.

Gangitano M, Mottaghy FM, Pascual-Leone A. Phase-specific modulation of cortical motor output during movement observation. Neuroreport 2001;12:1489-1492.

Guccione AA, Felson DT, Anderson JJ, Anthony JM, Zhang Y, Wilson PW, Kelly-Hayes M, Wolf PA, Kreger BE, Kannel WB. The effects of specific medical conditions on the functional limitations of elders in the Framingham Study. Am J Public Health 1994;84:351-358.

Hosseini L, Kargozar E, Sharifi F, Negarandeh R, Memari AH, Navab E. Tai Chi Chuan can improve balance and reduce fear of falling in community dwelling older adults: a randomized control trial. J Exerc Rehabil 2018;14:1024-1031.

Iacoboni M. Neural mechanisms of imitation. Curr Opin Neurobiol 2005; 15:632-637.

Kamide N, Shiba Y, Shibata H. Effects on balance, falls, and bone mineral density of a home-based exercise program without home visits in community-dwelling elderly women: a randomized controlled trial. J
Physiol Anthropol 2009;28:115-122.

Kawasaki T, Tozawa R, Aramaki H. Effectiveness of using an unskilled model in action observation combined with motor imagery training for early motor learning in elderly people: a preliminary study. Somatosens Mot Res 2018;35:204-211.

Kempen GI, Yardley L, van Haastregt JC, Zijlstra GA, Beyer N, Hauer K, Todd C. The Short FES-I: a shortened version of the falls efficacy scaleinternational to assess fear of falling. Age Ageing 2008;37:45-50.

Kovács É, Rozs F, Petridisz A, Erdős R, Majercsik E. Cross-cultural validation of the Falls Efficacy Scale-International to assess concerns about falls among Hungarian community-living older people. Disabil Rehabil 2018;40:3070-3075.

Lelard T, Doutrellot PL, David P, Ahmaidi S. Effects of a 12-week Tai Chi Chuan program versus a balance training program on postural control and walking ability in older people. Arch Phys Med Rehabil 2010; 91:9-14.

Liu-Ambrose T, Donaldson MG, Ahamed Y, Graf P, Cook WL, Close J, Lord SR, Khan KM. Otago home-based strength and balance retraining improves executive functioning in older fallers: a randomized controlled trial. J Am Geriatr Soc 2008;56:1821-1830.

Pelosin E, Barella R, Bet C, Magioncalda E, Putzolu M, Di Biasio F, Cerulli C, Casaleggio M, Abbruzzese G, Avanzino L. Effect of group-based rehabilitation combining action observation with physiotherapy on freezing of gait in Parkinson's disease. Neural Plast 2018;2018:4897276.

Rehman RZU, Del Din S, Guan Y, Yarnall AJ, Shi JQ, Rochester L. Selecting clinically relevant gait characteristics for classification of early Parkinson's disease: a comprehensive machine learning approach. Sci Rep 2019;9:17269.

Son NK, Ryu YU, Jeong HW, Jang YH, Kim HD. Comparison of 2 different exercise approaches: Tai Chi versus Otago, in community-dwelling older women. J Geriatr Phys Ther 2016;39:51-57.

Thomas S, Mackintosh S, Halbert J. Does the 'Otago exercise programme' reduce mortality and falls in older adults?: a systematic review and meta-analysis. Age Ageing 2010;39:681-687.

Tia B, Mourey F, Ballay Y, Sirandré C, Pozzo T, Paizis C. Improvement of motor performance by observational training in elderly people. Neurosci Lett 2010;480:138-142.

van Uden CJ, Besser MP. Test-retest reliability of temporal and spatial gait characteristics measured with an instrumented walkway system (GAITRite). BMC Musculoskelet Disord 2004;5:13.

Yoo HN, Chung E, Lee BH. The effects of augmented reality-based Otago exercise on balance, gait, and falls efficacy of elderly women. J Phys Ther Sci 2013;25:797-801. 